\title{
Undertaking PhD research in human geography in Ireland
}

\author{
Rob Kitchin
}

Published online: 22 August 2014

(C) Springer Science+Business Media Dordrecht 2014

\begin{abstract}
Over the past 15 years graduate education in the Republic of Ireland has been radically transformed through the introduction of new funding schemes, structured doctoral programmes, and enhanced research capacity, supports and infrastructures in Irish higher education. The result has been a rapid expansion of graduate numbers, inter-institutional and interdisciplinary collaboration in the delivery of graduate programmes, and a marked change in the resources available to support graduate students (albeit tempered by the post 2008 crisis). This short paper provides a critical but sympathetic commentary on $\mathrm{PhD}$ reform in Ireland.
\end{abstract}

Keywords $\mathrm{PhD} \cdot$ Ireland $\cdot$ Collaboration $\cdot$ Interdisciplinarity · Graduate education programmes (GREPs)

\section{Introduction}

Over the past 15 years graduate education in the Republic of Ireland has been radically transformed through the introduction of new funding schemes, structured doctoral programmes, and enhanced

R. Kitchin $(\bowtie)$

NIRSA, National University of Ireland Maynooth,

County Kildare, Ireland

e-mail: rob.kitchin@nuim.ie research capacity, supports and infrastructures in Irish higher education. The result has been a rapid expansion of graduate numbers, inter-institutional and interdisciplinary collaboration in the delivery of graduate programmes, and a marked change in the resources available to support graduate students. The present financial crisis poses a threat to the sustainability of present graduate education, but despite funding cuts new programmes have remained resilient, providing high quality programmes.

\section{Human geography PhDs in Ireland pre-2000}

Prior to 2000 doctoral study in Ireland was very small in scale and limited primarily to three institutions (Trinity College Dublin; University College Dublin; University College Cork). Up until this time, the tradition within the discipline was that the brightest students would emigrate to undertake their graduate research, most usually to the UK, USA and Canada. There were three main reasons underpinning this situation. First, Irish departments were small in size, typically less than ten academics, and pedagogically it made sense for students to move to larger departments where they would receive a broader education and training. Second, Irish institutions were poorly resourced and lacking institutional infrastructure with respect to libraries, laboratories and student supports. Indeed, it is only in the past 15 years that Irish universities have rolled out research support, graduate 
student and international student offices, with their own Deans/Vice-Presidents and support staff and programmes. Third, funding to support graduate students was very limited, with no national scholarship scheme and limited institutional support beyond occasional teaching. Most students supported themselves with paid work outside of academia or teaching and demonstrating work or working as research assistants on funded projects (usually contract research or funded by European programmes). The result was only a handful of graduate students in the Irish university system in any one year.

\section{Introduction of funded programmes}

This limited and ad hoc system started to be reconfigured at the turn of millennium, with a transformation of the funding landscape and institutional reform within the third level sector, leading to doctoral programmes across all seven geography departments in the Republic. In 1998 the Higher Education Authority announced a new programme of research funding designed to significantly and rapidly ramp up research capacity in Irish institutions. The Programme for Research in Third Level Institutions (PRTLI) sought to create new research institutes, fund new dedicated research space and specialised equipment, fund research support staff, and provide scholarships for doctoral students and postdoctoral researchers. Rather than fund individuals or specific projects, the programme aimed to produce new entities that could actively compete for funds both nationally and internationally, and thus provide a sustainable platform for facilitating research into the long-term. Given the small size of both academic departments and Irish institutions, the programme explicitly encouraged interdisciplinary and inter-institutional collaboration. The competition for the first cycle of funding ran in 1999, with the successful programmes running 2000-2003. Since then five cycles of funding have been awarded on a competitive basis, with over a billion euros of funding allocated.

Five of the PRTLI-funded institutes or programmes have strong geographic themes and funded doctoral students in Geography: the Centre for Innovation and Structural Change (CISC) and the Environmental Change Institute (renamed the Ryan Institute) both centred in the National University of Ireland Galway; the National Institute for Regional and Spatial Analysis (NIRSA) a collaborative venture between the National University of Ireland Maynooth, Institute of Technology Sligo, Mary Immaculate College Limerick, and Queen's University Belfast; the Urban Institute Ireland in University College Dublin (renamed the Earth Institute); the Environment Research Institute in Cork; and the Irish Social Sciences Platform (ISSP) that links together research across eight institutions, including CISC and NIRSA. Funded under Cycle 4, the ISSP funded $54 \mathrm{PhD}$ students, 16 postdocs, and several support staff, and was united around three themes: balanced development, knowledge societies and sustaining communities.

The PRTLI programme was accompanied by the establishment of the Irish Research Council for Humanities and Social Sciences (IRCHSS), the Irish Research Council for Science, Engineering and Technology (IRCSET), and Science Foundation Ireland $(\mathrm{SFI})^{1}$ in 2000. All three funded individual scholars and specific projects, including large numbers of doctoral students. In addition, SFI also funded the establishment of new research institutes and collaborations, and a large-scale research collaborations between institutions. Such funding led to the establishment of the National Centre for Geocomputation in NUI Maynooth in 2004 and the StratAG (Strategic Research in Advanced Geotechnologies) programme running from 2009 to 2013 that funded a number of doctoral and postdoctoral researchers.

These new funded programmes dramatically transformed the research landscape in Ireland and the number of doctoral students across the entire system. Indeed, they started to provide research routes from the undergraduate level (internships) through masters programmes to $\mathrm{PhD}$ scholarships to postdoctoral work. The role out of these programmes was the result of five main drivers. First, within the universities and certain sections of government there was a recognition that the higher education landscape in Ireland needed to transform to catch-up with and match institutions in other countries, and that the numbers of graduate students needed to grow significantly in order to create and sustain an innovation and

\footnotetext{
${ }_{1}$ Science Foundation Ireland (SFI) was initially established as a sub-board of Forfas (Ireland's policy advisory board for enterprise, trade, science, technology and innovation) in 2000, becoming its own agency in 2003 .
} 
knowledge economy. Second, pressure was exerted by multinational companies and development agencies for a general upskilling of Ireland's research base to support the competitive development of the economy in general. Third, it was clear that to access significant European Union funding for research, national research support infrastructure needed to be put in place and research support and capacity in the universities enhanced. Fourth, the government's finances had been changed markedly through the Celtic Tiger boom and, for the first time since independence, the government had sufficient funds to invest in research. Fifth, other entities such as Atlantic Philanthropies forced the government's hand with respect to the scale of funding by offering significant monies for research, but only on a matching basis.

\section{Introduction of structured programmes}

Traditionally, $\mathrm{PhD}$ students in Ireland have undertaken an independent programme of research consisting of preparation work, fieldwork, and an analysis and write-up phase. In theory, doctoral research was meant to last 3 years, but in practice lasted much longer due to funding issues. Training, as such, consisted largely of supervision by a primary advisor, attending departmental seminars and national/international conferences, and discussing work with other staff, academic visitors, and other students.

Accompanying the development of funded programmes has been a shift to structured graduate education programmes (GREPs). Initially, these were rolled out in Geography in an informal way. For example, the Irish Postgraduate Training Consortium for Geography held its first annual weekend meeting in 2000, bringing together staff and students from Irish institutions North and South to run a series of workshops relating to methodology, substantive research questions, and professional development. Through its PRTLI cycle 2 funding and some funding from the IRCHSS, NIRSA in NUI Maynooth ran a number of optional modules aimed at doctoral students on a range of themes (2001-2004) and a series of master classes in social science methodologies with international speakers (2004-06).

Since the mid-2000s, the Irish research agencies have sought to make structured $\mathrm{PhD}$ programmes a core element of doctoral programmes. The belief is that training leads to a higher quality thesis through advanced, supporting pedagogy and more focused and timely research, and ensures graduate students have a broad range of high-level knowledge and methodological and professional skills needed for academic and non-academic careers. The IRCHSS administered a number of funding calls for scoping out such programmes, and PRTLI cycles 4 and 5 and the Strategic Innovation Fund (SIF) of the Higher Education Authority have explicitly funded such programmes. These funding sources are mirrored at the European level by the Erasmus Mundus programme that funds inter-country (with a minimum of three states) structured doctoral programmes.

The Irish Social Sciences Platform (ISSP), for example, was funded under PRTLI 4 to provide an interdisciplinary and inter-institutional GREP that consisted of summer and winter schools, modules on methodology, specialist topics, and professional development, and arrangements for shared supervision of students across disciplines and partner institutions. Running the programme across disciplines and sites was designed to provide a critical mass of students for the courses and open up expertise across the Irish HE system to all students regardless of institution. A similar GREP in Politics, Sociology and Public Policy was funded by SIF, cycle 2. In some Irish universities it is now the case that all newly registered doctoral students have to undertake a structured $\mathrm{PhD}$ programme of at least 30 credits. One consequence has been to shift the expected timeframe of doctoral studies from 3 to 4 years, with funding from the research agencies now lasting that amount of time.

\section{Conclusion}

Studying for a $\mathrm{PhD}$ in Ireland has undergone enormous change over the past 15 years. There has been rapid expansion of student numbers, the rollout of a range of funding programmes, an internationalisation of students and staff, and the development of structured graduate education programmes. Graduate research increasingly takes place within inter-institutional and interdisciplinary collaborations, and doctoral study is moving to be 4 years in duration. The latest innovation to be adopted, at least in one university (NUI Maynooth), is undertaking a doctoral thesis by 
publication rather than a traditional dissertation. In this instance, students can submit a portfolio of three refereed, published articles, topped and tailed by an introduction and conclusion chapter.

This transformation has not been without its issues including resistance to the structured programmes by those favouring a more traditional mode of study, the bedding-in of inter-institutional arrangements, the lack of sustainable funding after the initial injection of funds to initiate programmes, and the over-production of graduates with few post-PhD career routes, especially in academia. Moreover, in the wake of the financial crisis in Ireland postgraduate funding has been drastically reduced, especially in the humanities and social sciences, and research funding in general has been moved into the remit of the Department for Jobs, Enterprise and Innovation and re-orientated to have a strong focus on applied and instrumental research which requires matching industry and nonexchequer (philanthropy) funding. What this means is that the research and graduate studies capacity built up over the last number of years is being systemically eroded. Nonetheless, graduate student numbers remain at a high level despite the cut-backs and Irish Geography departments and allied research institutes continue to provide a high quality and globally competitive graduate education. 